"Vox Patrum" 6/1986/z. 11

\title{
$\begin{array}{llllllll}\mathbf{R} & \mathbf{E} & \mathbf{C} & \mathbf{E} & \mathbf{N} & \boldsymbol{Z} & \boldsymbol{J} & \mathbf{E}\end{array}$
}

\section{PATRYSTYKA W IRLANDZKIM ROCZNIKU "PERITIA"}

iv 1982 r. ukazal sie pierwszy tom nowego periodyku mediewistycznego: "Peritia. Journal of the Medieval Academy of Ireland"/ss. VIII + 416/, w latach 1983 i 1984 ukazały się dwa kolejne tomy /ss. VIII + 318; XII + 598/. Jako wydawca dwóch pierwszych tomón eiguruje Donnchadh 6 Corrain $z$ uniwersytetu w Cork, w tomie III zaś występuje juz z kilku Innymi uczonymi Michael Richter, Dáibhí 6 Cróinf́n, Gearóld Mac N1ocaill/ i przy współudziale dalszych. W znacznie szerszym gronie rady redakcyjnej/Consultative Committee/ znalazł się również prof. Aleksander Gieysztor z Warszawy. Chociaż wydawcy nie określ1li nigdzie wyraźnie charakteru nowego pisma, to jednak daje sie on ratwo odczytać z jego kamów. Obejmuje wį̨c całe średniowieoze, co należy podkreślić, gdyz późniejsze fazy tego olzresu pozostawały dotąd wyraźnie w cieniu, jako że uczeni koncentrowali się raczej na wczesnym średniowieczu, kiedy to Irlandia i Iryjezycy odgrywall istotna rolę w dziejach kultury europejskiej. Periodyk przynosi różnej objętości rozprawy 1 artykuły naukowe, przyczynki źródłowe 1 dyskusyjne, artykuły recenzyjne 1 recenzje/zróżnicowane pod względem obszerności 1 szczegółowości/ oraz nekrologi. Wśród autorów, poza Irlandczykami, spotykamy przedstawicieli również innych krajów. Układ pisma jest dość elastyczny. W każdym z trzech dotąd dostępnych recenzentowi tomów zaznacza sį dość zwarty blok artykułów skupionych wokól jednego problemu. Tymi punktasi cizźkości poszczególnych tomów sz: hagiografia /I/, roczniki 1 historiografia średniowleczna /II/, Beda 1 jego świat /III/. Obserwujemy tendencję do wyodrąbniania się stałych działów, takich jak hiberołacina /Insular Latin, I, II, III/, komputystyka /I, II, III/, monastycyzm wyspiarsk1/I, II, III/, archeologla/I, III/. W tomie III pojawiły się dalsze działy: prawo iryjskie, późniejsze średniowiecze, historiografia /nowożytna/. If tomach I 1 III zamieszczono takze rozprawy poświęcone pamięci zmarłego w $1981 \mathrm{r}$. mediewisty z Dublina Denisa Bethella /por. jego nekrolog w t. I, 412-414/.

W niniejszym przeglądzie ograniczymy się do tych pozycji, które bezpośrednio lub pośrednio dotycz okresu do pierwszej por. VIII 
w., tradycyjnie nazywanego okresem patrystycznym w dziejach piśmiennictwa chrześcijańskiego. Spośród 9 rozpraw 1 artykułów zgromadzonych w tomie I, a dotyczących hagiografil 1roszkockiej, staroanglelskiej 1 skandynawskiej, wymienimy prace: Patrick H. Zettel, "Saints' Lives In 0ld English: Latin Manuscripts and Vernacular Accounts: Aeleric" /I 17-37/, J. E. Cross, "Saints' Lives in 0ld English: Latin Manuscripts and Vernacular Accounts: the "0ld English Martyrology"/I38-62/. Dwie prace dotyczą św. Brygidy: Richard Sharpe, "Vitae S. Brigitaen: the 0ldest Texts" /I 81-106/ 1 Kim MacCone, "Brigit in the Seventh Century: a Saint with Three Lives?" /I 107-145/. Ian Wood przedstawiz "The "Vita Columbani" and Merovingian Hagiography" /I 63-80/. J. M. Picard zajął się zywotem św. Kolumbana Starszego autorstwa Adamnana $z$ Hy /Iona/: "The Purpose of Adomnán's "Vita Columbae" /I 160-17T/, a Máirf́n Nf Dhonnchadha - zabytkiem prawnym zwanym Cáin Adomnán /lub: Lex Innocentium/, ogłoszonym przez tegoz Adamnana w 697 r. w celu ochrony kobiet, dzieci 1 duchownych oraz wasnośc1 kościelnej przed następstwami wojen /The Guarantor L1st of "Cá1n Adomnáin", 697; I 178215/. Dw1 dalsze prace dotyczace Adamnana ukazały się w III tom1e "Peritia": Jean-Michel Picard, "Bede Adomnán and the Writing of History" /III 50-70/ i A. D. S. Mac Donald, "Aspects of the Monastery and Monastic Life in Adomnán's Life of Columba"/III 271-302/. Na uwage zasługuje takze artykuł Pádraiga 6 Riaina, "Towards a Methodology In Early Ir1sh Hagiography" / I 146-159/, w którym zwrócono m.1n. uwage na aspekty ustnego przekazu zymotów świętych 1roszkockich w społeczeństwie tradycyjnie przywiazanym do tej formy przekazu. Interesujaca rozprawa Jørgena Hojgaarda Jørgensena, "Haglography and the Icelandio B1shop Sagas" /I 1-16/, dotyczy juz późniejszego okresu.

Dzial historiograficzny w II tomie "Peritia" takze liczy 9 pozycj1. Otwiera go artykuł Karla Brunnera, "Auf den Spuren verlorener Traditionen" /II 1-22/, w którym autor próbuje wskazać na pewne "nieoficjalne", a w kazdym razie nieidentyczne z tradycja pielegnowana na dworze karolińskim wątk 1 zachowane w "Annales Laureshamenses" 1 "Annales Nazariani", dotyczące waznych antyerankijskich powstań 1 rokoszów wezesnych lat panowania Karola Wielkiego /powstanie Hardrada w Turyngil 1 bunt Tassilona III w Bawari1/.

Annalistyka irlandzka reprezentowana jest kilkoma erudyeyjnym1 studiami, zawierającymi niekiedy edycje nieznanego dotą materiału źródłowego,jak: Dáibhí 6 Cróinin, "Early Irish Annals from Easter-Tables: a Case Restated" /II 74-869/ zajaz sie pgczatkami annalistyki w Irlandil 1 jej geneza w zwlazku z tablicaml 
paschalnymi. Ze względu na specyeiką annalistyki, której fillacje decyduja nieraz o znaczeniu danego rocznika, nawet dla odleglejszych w czasie okresón, wymienimy tu Jeszcze prace: David N. Dumville, "Some Aspects of Annalistic Writing at Canterbury in the Eleventh and Early Twelfth Centuries"/II 23-57/ 1 Dagmar 6 Riain-Raedel, "Twelfth-and Thirteenth-Century Irish Annals in Vienna" /II 127136/ / Wiedniu 18tniał wówczas konwent benedyktynów "szkockich" czyl1 1ryjskich/. Dwie kolejne prace dotycza powiązań historycznych 1 historiograficznych pomiędzy Irlandia a północnz Anglia Northumbria/: IIIermann Mo1sl, "The Bernician koyal Dynasty and the Irish In the Seventh Century" /II 103-126/ i R/ichard/ Sharpe, "Were the Irish Annals Known to a Twelfth-Century Northumbrian Writer?" /II 137-139//chodzi o anonimowe dzieło "Libellus de itivitate S.Cuthbert1 de historils Hibenensium exceptus et translatus"/. Wymienizbym równieź prace P. R. Ortona, "King Alfred's Prose "Preface" to the 0ld English "Pastoral Care" /II 30-41, 140-148/ - kolejny przyczynek do działalności kulturotwórczej króla Alfreda Wielkiego, tym razem w zwiłzku ze staroangielskim przekładem "Reguły pasterskiej" Grzegorza Wielkiego.

Postać Bedy Czcigodnego, zamykającego jak gdyby epoke patrystyczna, zajmuje sporo miejsca na łamach "Peritia". W tomie II, 7 dziale "komputystyka", znalazł się artykuł Dáibhf 6 Cróinín, "The Irish Provenance of Bede's Computus" /II 229-247/. W tomie III, Jak juz wspomniałem, Beda 1 jego czasy stanowiz punkt cięzkośc1. Wybitny znawca powił̨zań hiszpańsko-1 ryjskich we wczesnym f́redniowieczu J. N. Hillgarth kontynuuje 1 pogłębia swoje dawniejsze badania z tej dziedziny ${ }^{1}$ /Ireland and Spain in the Seventh Century: III 1-16/. Dalsze pozycje "bloku bedańskiego" to: Dáibhf ó Cróinfn, "Rath Melsigi, Willibrord, and the Earliest Echternach Manuscripts" III 17-49/w aneksie do tej rozprawk1, na s. 43-49, zamieszczono tekst

1 Por. J. N. Hillgarth, The East, Visigothic Spain and the Irish, w: "Studia Patristica" 4/1961/442-456; Visigothic Spain and Early Christian Ireland, "Proceedings or the Royal Irish dcademy" /C/ 62/1962/ 167-194; Old Ireland and Visigotilic Spain, w: old Ireland, ed. R. Nic Nally, Dublin 1965, 200-227. Do tej tematyki por. takize: M. Lerren, On the Earliest Irish Acquaintance with Isidore of Seville, w: Visigothio Spain: New Ypproaches, ed. E. James, Oxford 1980, 243-250. 
Thomasa Fanninga, "Some Field Monuments in the Townlands of Clonmelsh and Garryhundon, Co Carlow, będz̨cy pizyczynkiem do powi zzzań iryjsko-anglosaskich w okresie przedwikińskim/; wspomniany wyżej artykuł J.-M. Picarda o wpływie Adamnana na pisarstwo historyczne Bedy: Judith McClure, "Bede and the Life of Ceolfrid"/III 71-84/; Edward James, "Bede and the Tonsure Question" /III 85-98/; Michael nichter, "Bede's "Angli": Angles or English?"/III 99-114/. W tym ostatnim "Angli" zdaniem Autora w bedańskim opisie osadnictwa germarisklego $w$ Brytanil /Hist. eccl. I 15/ nie oznaczaja Anglów w sensie plemiennym, lecz ogół ludności anglosaskiej. "Historia ecclesiastica gentis Anglorum" była znana $i$ tłumaczona wóród Iroszkotów; problemowi temu poświęciła artykuł Próinséas Nf Chatháin, "Bede's Ecclesiastical History in Irish" /III 115-130/.

Jako druga pracę z seril "Denis Bethell Memorial Lecture" James Campbell zamieścił interesujace studium pt. "Some TwelethCentury Views of the Anglo-Saxon Past" /III 131-150/, skuplajac uwagz zwłaszcza na dziełach Henryka z Huntington 1 Wilhelma $z$ Malmesbury.

T dzialo hiberołaciny mamy do odnotowania następujące prace: J. 4. Picard, "The Schaffhausen Adomnán-a Unique Witness to Hiberno -Latin" /I 216-249/ - chodzi o rękopis "Vita Columbae"2; Vivien Law, "Notes on the Dating and Attribution of Anonymous Latin Grammars of the Early Middle Ages" /I 250-267/; czæ̧ściowo polemiczny w stosunku do nief artykuł Louisa Holtza, "Les grammairiens hiberno-latins étalent-1ls des Anglo-Saxons?" /II 170-184/.

Dodajmy, ze podstawowa monografia dziś niewątpliwie najlepszego znarcy zagadnioń owczesnej gramatyk1 L. Holtza, "Donat et la tradition de l'enseignement grammatical: Étude sur l'"Ars Donati" et sa diefusion /IV $V^{e}-X^{e}$ siècle/ et édition critique"/Paris 1982/, znana takie polskiemu czytelnikowi dzį̧ki omówieniu przez Brygidę Kurbis ${ }^{3}$, została omówiona takze w II tomie "Peritia" przez Dáibhí $\delta$ Cróinf́n/II 307-311/. Także monografia Vivien Law, "The Insular

2 o ile mi wiadomo, J. M. Picard przygotowuje nowa edycja tego utworu.

3 "Studia Źródłoznawcze" 28/1983 217-219. 
Latin Grammarians" Noodbridge, Suffolk 1982/, została omówiona przez Lichaela Herrena/II 312-316/.

A oto dalsze prace zaszeregowane przez Wydawców do działu "hiberołaciny": Seán Connolly, "Verbal Usage in "Vita prima Brigitae" and "Bethu Brigte" /I 268-272/; Michael Herren, "Insular Latin "C/h/araxare" /craxare/ and Its Derivatives" /I 272-280/; Jean Rittmueller, "The Gospel Commentary of Máel Brigte a Máeluanaig and Its Hiberno-Latin Background" /II 185-214/; David Wasserstein, "Semitica Hiberno-Latina" /II 215-224/, dotycząca dwóch szczegółów z XIV-wiecznego dzieła eranciszkanina Irlandzkiego "Itinerarium Symonis Semeonis ab Hybernia ad Terram Sanctam"/ed. M. Esposito, Script. Lat. Hiberniae 4, Dublin 1960/; Rolf Baumgarten, "A HibernoIsidorian Etymology" /II 225-228/; Damian MicManus, "Linguarum diversitas": Latin and the Vernaculars in Early Medieval Britain" /III 151-188/; Rolf Baumgarten, The Geographical Orientation of Ireland in Isidore and orosius /III 189-203/ - zamieszczenie tef rozprawki w dziale Językoznawczym należy uznać za niewłaściwe ${ }^{4}$; Aidan Breen, "Some Seventh-Century Hiberno-Latin Texts and Their Relationships" /III 204-214/ - artykuz dotyczy powi łzań pomiędzy kilkoma tekstami egzegetycznymi pochodzenia południowoiryjskiego/wydanymi niedawno w 108 B tomie Corpus Christianorum/, "Collectio Canonum Hibernienslum" oraz dziełami zagadkowego autora znanego pod imieniem Virgilius Maro; Jean Rittmueller/por. wyżej/, "Postscript to the Gospels of Máel Brigte/III 215-218/; David Wasserstein/por. wyżej/, "Semitica Hiberno-Latina III: Symon Semeonis on the Sultan's Slaves in 0ld Ca1ro"/III 219-221/.

W dziale komputystyka znalazły się, oprócz wymienionej juź pracy 6 Cróinína o 1ryjskiej genezie komputu Bedy, następujzce artykuły: Dáibhí $\delta$ Crótinin, "Mo-Sinnu moccu Min and the Computus of

4 Analizując dane o położeniu Irlandif zawarte u Izydora 1 orozjusza, Baumgarten zwrócił uwagę na nleoczekiwan̨ w dziełach o tym stopniu ogólności precyzjô w określaniu rozciłgłości xyspy: "ab Africo in Boream" /od płd. zach. na pn. wsch./. Zdaniem Autora Izydor korzystał "tym miejscu z dzieła Orozjusza, natomiast natchnieniem dla orozjusza iniała by być jakaś wersja mapy Ptolemeusza, której informacje hiszpański autor skombinowaz $z$ danymi wywodzacymi sie ostatecznie z dzieła Cezara. Orozjuszowa koncepcja bliskiego sqsiedztwa Hiszpanif 1 Irlandil została podchwyoona później przez sanych Iryjczyków 1 legła u podstaw podania o podboju Irlandil przez Milezyjczyków z Hiszpani1. Por. przekład chorografil Pawła Orozjusza Historiarum adversus paganos 
Bangor /I 281-295/ - na podstawie zapiski w 1ryjskim rękopisie w Wurzburgu, Univ. Bibl. MS M. p. th. 1. 61; David N. Dumville, "Motes and Beams: two Insular Computistical Manuscripts /II 248 -256/ - jest to polemika z uwagami ó Cróinina zamieszczonymi w I tomie "Peritia" /407-408/; D. 6 Cróinín, "Sticks and Stones a Reply" /II 257-260/ - to z kolel replika na poprzedni artykur; Kenneth Harrison, "A Letter Prom Rome to the Irish Clergy, AD 640" /III 222-229/ - zw1 zzku z kontrowersja paschalnz.

Dzial "monastycyzm wyspiarski": Charles Doherty, "Some Aspects of Hagiography as a Source for Irish Economic IIstory" /I 300-328/ artykuł dotyczy głównie wczesnego średniowiecza. Niezbyt słusznie do tego dziaiu został zakwalifikowany przyczynek A. D. S. MacDonalda, "Notes on Terminology in the Annals of Ulster, 650-1050" /I 329-333/. Poza tym: Francis J. Byrne, "Monastica et onomastica" /II 261-264/; T. E. McNeill, "The Premonstratensian House of Carrickfergus, White Abbey and Foodburn" /II 265-266/; K. W. Nicholls, "A Charter of John; Lord of freland, in Favour of Matthew Ua Hénni, Archbishop od Cashel" /II 267-276/; gruntowny artykuł Richarda Sharpe, "Some Problems Concerning the Organization of the Church In Early Medieval Ireland"/III 230-270/; wymieniony wyzej artykuł MacDonalda o zyciu klasztornym w "Vita Columbae Adamnana"; Charles Doherty, "The Bas1l1ca in Early Ireland" /III 303-315/. Charakter przyczynków mają: F. J. Byrne, "A Note on Trim and Sletty" /III 316-319/ - chodz1 - legendy fundacyjne tych dwóch kościołów; Pádraig 6 Riain, "Samson allas San/c/tán?"/III 320-323/ - rzecz dotyczy śk. Samsona $z$ Dol w Bretan11; Conleth lanning, "St Buite, Nellifont and Toberbolce" /III 324-325/; Anthony Candon, "náith Bressall: a Suggested Identification" /III 326-329/ - synod $\sigma 1111$ roku.

W dziale archeologicznym znalazły się, jak dotąd, dwie rozprawy: Egon Wamers, "Some Eccleslastical and Secular Insulat Metalwork Found in Norwegian Viking Graves"/II 277-306/ oraz praca zbiorowa piqciu autorów: "Six Silver Finds of the Viking Period From the Vioinity of Lough Ennell, Co Westmeath"/III 334-381/. Obie rozpraw-

przekład chorografil Pawła Orozjusza H1storiarum adversus paganos I 2, pióra K. Obryckiego, "Vox Patrum" 4/1984/, z, 6-7, 392-410 /0 Irland11 8. $405 \%$ 
k1, Jak na archeologiczne teksty wypadało, sa bogato 1lustromane reprodukcjam1 zabytków.

W zalnaugurowanym w III tomie "Peritia" dziale "prawo 1ryjakie" znajdujemy dwie rozprawki. Pierwsza z nich, pióra Donnchadha 6 Corráina, Liama Breatnacha 1 Aidana Breena, "The Laws of the Irish" /III 382-438/ - jest to obszerne 1 krytyczne omóvienie monumentalnej edycj: zabytków prawa staroiryjskiego, opublikowanej przed kilku laty, edycji która umozliwiła /przynajmniej osobom znającym Język staro1ryjaki/ wełni źródłowe studium bogatej twórczości prawniszej wczesnośredniowlecznej Irland1 $1^{5}$. Druga rozprawa: Llam Breatnach "Canon Law and Secular Law in Early Ireland: the Significance of "Bretha Nemed" /III 439-459/, dotyczy f́rodkowoiryjek1ego poematu powstałego według wymodó Autora w pierwszej poł. VIII w. $\$$ prow1noj 1 Munster.

z działu "późniejsze éredniowiecze" wspomnimy jedynie cenny artykuł Yolande de Pontrarcy, "Le Tractatus de Purgatorio Sanct1 Patricil" de H. de Saltrey: sa date et ses sources" /III 460-480/, ze względu na postać św. Patryka; w dzlejach legendy narastajacej wokóz tej postaci dwunastowleczny traktat wymieniony " tytule rozprawki odegrał istotną rolę.

Jedyna Jak dotąd pozycja w dziale "historlografia"/nowozytna/ jest artykul Glenna T. Wrighta, "James F. Keniney/1884-1946/" /III 517-534/. Jest to jedyna właściwie naukowa biografla wybitnego uczonego, autora podstawowej od niemal 60 lat 1 clagle nie zastapionej publikacj1 "The Sources for the Early History of Ireland" 6 . c Moźna tutaj wspomnteć o dziale nekrologów, wśród których spotykany nekrologi uczonych znanych z badań nad wczesnośredniowieczna Irlandiz, takich Jak Denis Bethell/1934-1981/, Maurice Keen /I 412 $-414 / 7$.

5 Corpus Iuris Hibernici, vol. I-VI, ed. D. A. Binchy, Dublin 1978.

6 Ukazał sie jedynie tom I: J. F. Kenney, The Sources for the Early History of Ireland: Ecclesiastical. An Introduction and Guide, N. York 1929 /przedruk1: $196611979 /$.

7 Podobizna D. Bethella na pocz ttku III tomu "Peritian. 
W rozbudowanym dziale recenzji /od obszernych artykułów recenzyjnych po zwięzłe noty/ na uwage zasługuja omówienia nastǫpuJacych prac: A. P. Smyth, Scandinavian York and Dublin: the History and Archaeology of Two Related Viking Kingdoms, t. 1-2, Dublin 1975-1979 /R. I. Page/, /I 335-351/; The Durham Gospels, Durham, Cathedral Library, IS A. II. 17, seria: Early English Manuscripts In Facsimile, vol. 20, Copenhagen 1980, /D. 6 Cróinf́n/, /I 352-362/; The Patrician Texts in the Book of Armagh, ed. L. Bieler/Script. Lat. Hib. 10/, Dublin 1979 /R. Sharpe/, /I 363-369/; Insular Latin Studies: Papers on Latin Texts and lianuscripts of the British Isles: 550-1066, ed. M. Herren, Toronto 1981, /D. 6 Cróinín/, /I 404-409/; wymienione juz artykuły recenzyjne prac Holtza 1 Lawa o gramatyce wczesnó́redniowiecznej/por. wyżej/; A. P. Smyth, Celtic Leinster: Towards an Historical Geography of Early Irish Civilization, A. D. 500-1600, Dublin 1982, /K. W. Nicholls/, /III 535-558/; T. W. Moody, F. X. Martin, F. J. Byrne/ed./, A Chronology of Irish Bistory to 1976: a Companion to Irish History /A New History of Ireland $8 /$, Oxford 1982, N. Davies i D. Tierney/, /III 559-566/; W. Dav1es, Wales in the Early Middle Ages. Studies in the Early History of Britain, Leicester 1982, /P. $6 \mathrm{Riain/,} \mathrm{/III} \mathrm{567-569/;} \mathrm{Alfred} \mathrm{the}$ Great: Asser's "Life of King Alfred" and Other Contemporary Sources, tłum. 1 wyd. S. Keynes 1 M. Lapidge, Harmondsworth 1983, R. Sharpe/, /III 570-572/; The Anglo-Saxon Chronicle, vol. 4, ed. S. Taylor, Cambridge 1983, /D. R. Howlett/, /III 573-575/; D. W. Rollason, The Mildrith Legend. Studies in the Early History of Britain, Leicester 1982, /E. John/, /III 576-578/; Folla Gadelica/ksiega pamigtkowa dla R. A. Breatnacha/, Cork 1983, M. A. G. 8 Tuathaigh/, /III 585$589 /$.

Jak wynika $z$ powyzszego przeglądu, badan1a nad dzlejami Irland11 1 Iroszkotów we wczesnym éredniowieczu, kiedy to udział tego ludu w rozmoju kulturalnym duzej częśc1 Europy był nadspodziewante znaczny, wykazuja duzą dynamikę 1 światowy zasieg. Równocześnie nie zaniedbuje sie juz dziejow Irland11 w póniejszym sredniowieczu, waznych z innego punktu widzenia - zwiaszcza w badan1ach porównawczych nad kształtowaniem siq narodów europejskich. Dzięk1 "Peritia" 1 Ledieval Academy of Ireland dorobek tych badań staje ste latwiej uchwytny 1 dostepny Innych krajach. 